\title{
On the Formation of Critical Thinking of Students of a Higher Educational Institution
}

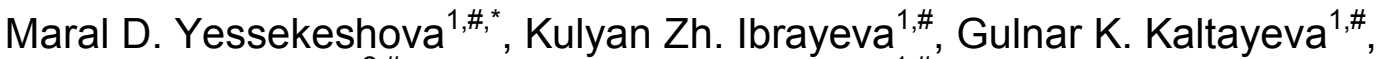 \\ Nazymgul Albytova ${ }^{2, \#}$ and Zhanar S. Bekbayeva ${ }^{1, \#}$
}

\author{
${ }^{1}$ Department of the Professional Education, S. Seifullin Kazakh Agro Technical University, Nur-Sultan, \\ Republic of Kazakhstan \\ ${ }^{2}$ Department of Social Pedagogy and Self-Knowledge, L.N. Gumilyov Eurasian National University, Nur- \\ Sultan, Republic of Kazakhstan
}

\begin{abstract}
Objective: The paper examined for the first time the features of the formation of systemic critical thinking of students of a higher educational institution, using systemic methods specially developed for this.

Background: Unfortunately, there is practically no specific technology or even a method that specifically solves the problem of forming critical thinking. Nevertheless, each person who did not even receive the skills of critical thinking in the learning process possesses this type of thinking to some extent

Method: The method of systemic structuring and studying information about the objects in question solves important tasks of developing ways of thinking that are very relevant for future specialists. Implementing the methods of systemic cognition of the studied objects and the surrounding reality ensured the development of the systematic knowledge, skills, and systemic and other relevant ways of thinking and a systematic approach in cognitive and other activities.

Results: The peculiarity of what has been said is that students in the process of implementing this method learn and develop simultaneously the proposed types of activities (actions) and the corresponding ways of thinking, including critical ones, determined by them. The particularly important result of the implementation of a systematic approach and systematic methods developed on its basis is the formation of systematic-critical thinking.

Conclusion: The concept of systematic-critical thinking has been developed. Using a systematic approach as a scientific method allowed to significantly transform not only theory and practice but also existing traditional technologies of the formation of critical thinking.
\end{abstract}

Keywords: Educational process, methods of cognition, teaching methods, research methods, work with text.

\section{INTRODUCTION}

As our studies have shown, traditional technologies for the formation of critical thinking generally do not imply the need to study the whole, relying mainly on the results of critical analysis. It is hardly possible to develop one's critical judgment or conclusion about the phenomenon studied, without considering its holistic, in a wider context. Moreover, for the most part, the existing technologies for the formation of critical thinking are only a combination of various known technologies and methods of problem, active, activity, etc. learning. Unfortunately, practically no specific technology or even a method specifically solves the problem of forming critical thinking. Nevertheless, each person who did not even receive the skills of critical thinking in the learning process possesses this type of thinking to some extent.

The situation is such that practically the same mechanisms underlie the methods of a systematic

*Address correspondence to this author at the Department of the Professional Education, S. Seifullin Kazakh Agrotechnical University, Nur-Sultan, Republic of Kazakhstan; Tel: +77172398018; E-mail: bekbayeva5125@ubogazici.in

"These authors are equally contributed. approach that the authors propose and the idea of forming critical thinking of students with intellectual disabilities. Simultaneously, the methods of the system approach that the authors propose allow solving the broader tasks of active cognition of the surrounding reality, while forming the skills of systemic and other relevant (including critical) ways of thinking. In infantile cerebral palsy, there is not only a slow rate of mental development as a whole but also an uneven, disproportionate nature of the formation of individual mental functions.

The presence of disorders of the motor sphere, which limits the practical activity and significantly complicates the development of self-movement and self-care skills, contributes to the formation of passivity, lack of initiative in a person. In addition, such students have disorders of the emotional-volitional sphere, behavior, speech, vision, and hearing associated with early organic brain damage. Most students with cerebral palsy and intellectual disabilities are characterized by increased fatigue. They focus on the task for a long time, quickly becoming sluggish or irritable. Some students may experience motor anxiety 
due to fatigue: they become anxious, gesture, grimace, and more.

The article aims to study the features of the formation of systemic-critical thinking of students with psychological disabilities of a higher educational institution, using specially developed systemic methods. The novelty of this work is primarily in the actualisation and possibility of the formation of systemcritical thinking, as a new phenomenon of professional training for future specialists. Studies in the theory and practice of the formation of critical thinking of university students with cerebral palsy are actively developing, but the problem itself remains insufficiently studied [18].

\section{MATERIALS AND METHODS}

The following research methods were used in this work: work with text, the scientific method of a systematic approach, questioning methods, questioning and analysis of products of intellectual activity, quantitative and qualitative processing of the results of information received. The general scheme of working with educational material based on a systematic approach has several options for its implementation in the learning process of students with disabilities. At the same time, each paragraph of the text is subjected to analysis, in which the "main idea", the main thing, keywords, etc., are highlighted and entered into a special table. Then a collective discussion of the results is carried out based on which the final decision of the whole team (group, class) is recorded in the next column of the table. The main concepts, laws, patterns, formulas, etc., revealed in the process of paragraph analysis are included in a special column of the table.

Figure 1 shows a diagram of the analysis of the studied material, during which certain information (dark squares) is revealed, then the synthesis and graphic generalisation of the revealed information is carried out, then - the construction of a conceptual model of its system. Figure 1 shows the scheme of work with the material being studied, and it is intended for use in the educational process when studying textbooks and the educational material as a whole in order to identify skills of systemic critical thinking of students with disorders of the musculoskeletal system, as well as in evaluating the actions of students.

The survey of teachers was conducted by the method of contact questioning of those teachers who conducted and conduct training sessions in student groups in the speciality "Teacher" - participants in this experiment, in compliance with all the requirements for this kind of research. The purpose of the questionnaire: to determine the degree of awareness of teachers about teaching technologies aimed at the formation of critical thinking and which technologies they use in their teaching practice.

Another method is the method of analysis of products of intellectual activity. It was applied when disabled students performed independent work on the analysis of educational texts. This method was used in the teaching of the discipline "Psychology". Students with mental disorders were offered study texts that met the criterion of critical saturation of a study text, see Table 1 [9].

Students were offered study texts and instruction for working with this study text by M.V. Denisinkova [10] with authors' improvements, which included the formation of the following intellectual skills and personality traits. In this study, the authors relied on the following skills and mental operations (Table 2). On the other hand, in the authors' opinion, the implementation of this task requires students with cerebral palsy to form the following personality traits such as self-

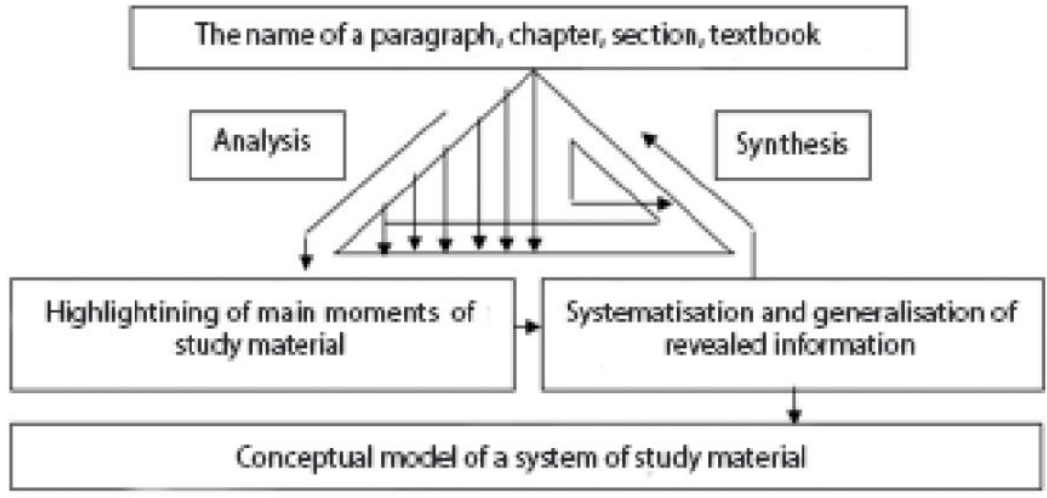

Figure 1: The scheme of work with the study material. 


\section{Table 1: Criteria for the Critical Saturation of the Study Text}

\section{\begin{tabular}{|l|l} 
Criterion of critical saturation of a & Fragments included in a training text
\end{tabular} study text}

1. The criterion of the necessity of understanding the real degree of truth of such fragments of knowledge that are traditionally considered as true 1a. The inclusion in the educational text of information about how legitimate an experimental confirmation of a known fact is and how confident one can be in an experiment confirms a theoretical position.

$1 \mathrm{~b}$. The inclusion in the text of information in which an author invites a reader to reflect on the legality of certain simplifications, neglects, assumptions about the insignificance of the influence of any factors on the course of the studied phenomenon, and abstracting from any condition. 1c. The inclusion in the educational text of information about widespread misconceptions with an analysis of their "roots" and the exposure of the falsity of what is proclaimed in them.

$1 \mathrm{~g}$. The inclusion of dialogue fragments in the educational text.

1d. The inclusion in the educational text of information about the mistakes and errors of great scientists, as well as material on how certain fragments of knowledge ceased to be truths, which until a certain point had been considered true.

2. The criterion based on the unity of symmetry and asymmetry

2a. The inclusion of information on differences of unreasonably identifiable constructs in the educational text.

$2 \mathrm{~b}$. The inclusion in the educational text of information about the internal similarity to a certain extent between illegally opposed constructs.

3. The equilibrium criterion 3a. The inclusion in the educational texts of information about the negative aspects of what is unduly unnecessarily absolutised in a positive quality.

3b. Inclusion in educational texts of information about the positive aspects of what is wrongfully absolutised in a negative sense.

\section{Table 2: Student Work with Study Text}

\begin{tabular}{|c|c|c|}
\hline Mental operation & Characteristics & The student's order of execution \\
\hline Analysis & $\begin{array}{l}\text { The mental decomposition of } \\
\text { the studied object into its } \\
\text { constituent elements and the } \\
\text { study of each element } \\
\text { individually as part of the } \\
\text { whole. }\end{array}$ & $\begin{array}{l}1 \text { To set the goal of analysis } \\
2 \text { To divide the studied object into system-forming elements (signs, properties, } \\
\text { relationships) } \\
3 \text { To examine each element separately. } \\
4 \text { To include the studied object in communication and relations with other } \\
\text { components of the phenomenon under consideration } \\
5 \text { To make a plan for studying the object as a whole }\end{array}$ \\
\hline Systematisation & $\begin{array}{l}\text { Mental operation of mixing } \\
\text { concepts into a specific } \\
\text { system }\end{array}$ & $\begin{array}{l}1 \text { The selection of the essential signs of phenomena (through analysis - synthesis) } \\
2 \text { Establishing links between essential features } \\
3 \text { Establishing common signs of the phenomena under consideration (using } \\
\text { comparison) } \\
4 \text { Generalisation of homogeneous phenomena in one group (using generalisation) } \\
5 \text { Classification of phenomena subject to classification }\end{array}$ \\
\hline Generalisation & $\begin{array}{l}\text { Mental association of objects } \\
\text { having common properties }\end{array}$ & $\begin{array}{l}\text { The structure of inductive generalisation: } \\
\text { 1) determination of the purpose of generalisation; 2) finding various signs of objects; } \\
\text { 3) determination of common features of objects; 4) formulation of conclusions } \\
\text { The structure of deductive generalisation: } \\
\text { 1) determination of the purpose of communication; 2) the allocation of a common } \\
\text { attribute of objects; } 3 \text { ) verification of the presence of a common attribute in each } \\
\text { subject; 4) the allocation of those items that have this feature; 5) formulation of the } \\
\text { conclusion }\end{array}$ \\
\hline $\begin{array}{l}\text { Establishing } \\
\text { causation }\end{array}$ & $\begin{array}{l}\text { Ability to determine cause } \\
\text { and effect in the studied } \\
\text { processes and phenomena }\end{array}$ & $\begin{array}{l}\text { 1) to analyse the studied phenomenon; } 2 \text { ) to establish the causes of this } \\
\text { phenomenon; } 3 \text { ) to determine all the ensuing consequences; } 4 \text { ) to establish the } \\
\text { interaction of cause and generated effects, to determine the significance of the } \\
\text { interaction. }\end{array}$ \\
\hline
\end{tabular}


Table 3: The Levels of Critical Thinking

\begin{tabular}{|c|c|c|c|}
\hline Indicators & High level & Medium level & Low level \\
\hline Intellectual skills & $\begin{array}{l}\text { The formed and firmly fixed } \\
\text { intellectual skills are realised. } \\
\text { Comprehensive relationship } \\
\text { between the studied phenomena } \\
\text { are indicated } \\
\text { there is an active search for new } \\
\text { ways of thinking when solving } \\
\text { problems } \\
\text { there is an independent } \\
\text { development of hypotheses, } \\
\text { discoveries, etc. }\end{array}$ & $\begin{array}{l}\text { Compliance with the order of mental } \\
\text { operations: } \\
\text { parts of objects or signs of phenomena } \\
\text { are listed in a certain sequence but } \\
\text { without the need for subordination } \\
\text { minor errors in the course of action are } \\
\text { allowed (error is stable) } \\
\text { certain difficulties in the implementation } \\
\text { of independent formulation of } \\
\text { conclusions (inherent in the activity from } \\
\text { a "template") }\end{array}$ & $\begin{array}{l}\text { The order of execution of the } \\
\text { mental operation is not } \\
\text { observed: } \\
\text { parts of objects or signs of } \\
\text { phenomena are listed in the } \\
\text { wrong sequence } \\
\text { violation of the order of mental } \\
\text { operations } \\
\text { the absence of certain stages of } \\
\text { mental operations } \\
\text { lack of self-correction and self- } \\
\text { esteem }\end{array}$ \\
\hline Personality traits & $\begin{array}{l}\text { High level of formedness of } \\
\text { personality traits }\end{array}$ & Formedness of personality traits & $\begin{array}{l}\text { Insufficient formedness of } \\
\text { personality traits }\end{array}$ \\
\hline Evaluation & $90 \%$ and higher & $70 \%-89 \%$ & $69 \%$ and lower \\
\hline
\end{tabular}

discipline, responsibility, creativity, independence, and self-regulation. In carrying out assignments, the experimenters were monitoring the progress of the assignment and assessing the personal qualities of students and self-assessment by students of the proposed personality qualities.

According to the results, students' work with the educational text was evaluated according to the following criteria and indicators, see Table 3.

This study was conducted within the walls of $S$. Seifullin Kazakh Agro Technical University (S. Seifullin KazATU) in the 2018-2019 academic year. The questionnaire was attended by 52 people from the faculty of "Computer Systems and Professional Education", which includes 5 departments: the department of vocational education, the department of higher mathematics, the department of information and communication technologies, the department of computer engineering and software, the department of physics and chemistry.

On the other hand, in this study, 65 people participated - 3-year undergraduate students in the amount of 42 people and 23 2-year students of the speciality "Vocational Training" - training teachers of technical disciplines for the college, S. Seyfullin KazATU.

\section{RESULTS AND DISCUSSION}

In the second semester of the academic year 20182019, the authors surveyed among the faculty of JSC Seifullina Kazakh Agro Technical University, the city of
Nur-Sultan in the amount of 52 people, whose teaching experience is 12 people up to 1 year, 2 people teaching experience is 5 years, 3 people -10 years, 14 people have 11 to 20 years of teaching experience, and 21 people from 21 to 46 years old, respectively (Figure 2).

Of the 52 teachers, 27 teach or taught classes in student groups of the speciality 5B012000 "Vocational training", which are participants in our experimental work. The questionnaire included teachers' awareness of the concept of critical thinking, the role of the formation of critical thinking of students with disorders of the musculoskeletal system. The questions were open and closed. The authors will present the results of a survey on the issues of used teaching technologies aimed at the formation of critical thinking of students (Figure 2).

Thus, $1 / 2$ of the teachers use problem-based learning as the main way to form critical thinking, $1 / 3$ of the teachers purposefully develop individual tasks and independent work tasks using critical thinking skills of students with special needs. In our opinion, the results of the survey show good prospects in obtaining high results in the formation of critical thinking of "special" students. However, the results of a frontal survey of students whether they know the concept of "critical thinking" and whether they can give a definition, caused difficulties for students in both the second and third courses of speciality 5B012000 "Vocational training".

As part of a lesson in psychology and psychology of management, students were offered educational texts 
Which methods and means of work do you use in educational process to form critical thinking in students?

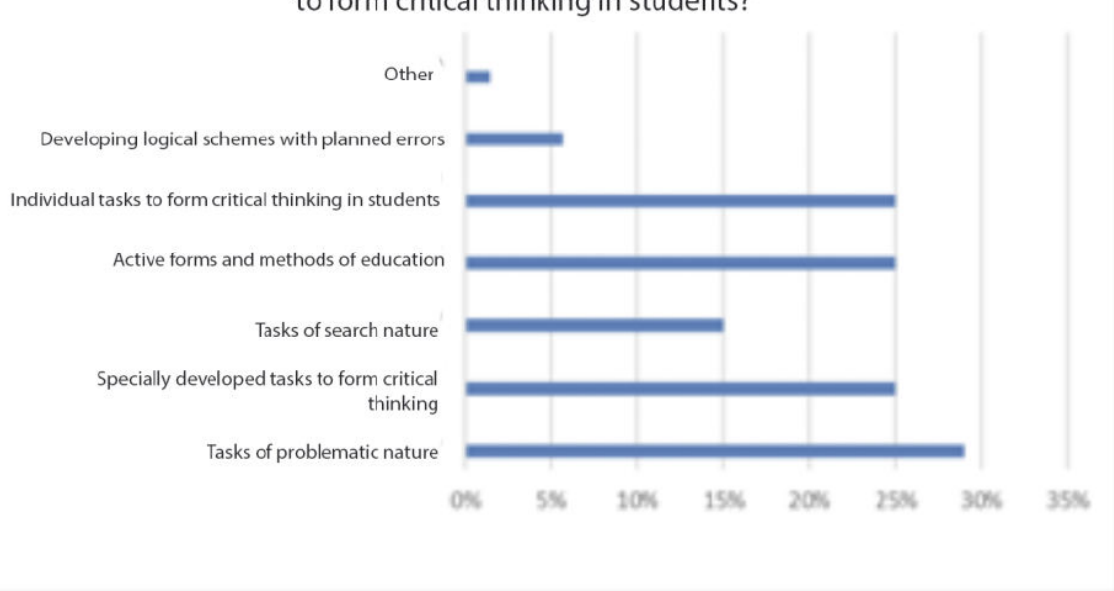

Figure 2: Answers to the question "What methods and means of work do you use in the educational process to form critical thinking in students?"

of a descriptive, problem-search, and problemreasoning nature, that is, of different levels of complexity. Time to complete the task - 100 minutes. Analysis of the products of students' activities showed the following results (Figure 3; Table 4).

Based on the results obtained, the authors note that despite the fact that teachers use various teaching technologies, including technologies aimed at creating critical thinking of students, the results of a survey and analysis of students' products show an insufficient level of formation of critical thinking skills and personal qualities student with disabilities.

The formation of critical thinking of students with cerebral palsy should be considered as a system. The key point here is the study of the object in its integrity. Every "approach" considers an object in a certain form of universal being. The systematic approach studies the form of things in the form of systems of different levels: macro, meso, micro, and of different quality (physical, chemical, biological, etc.). The very concept

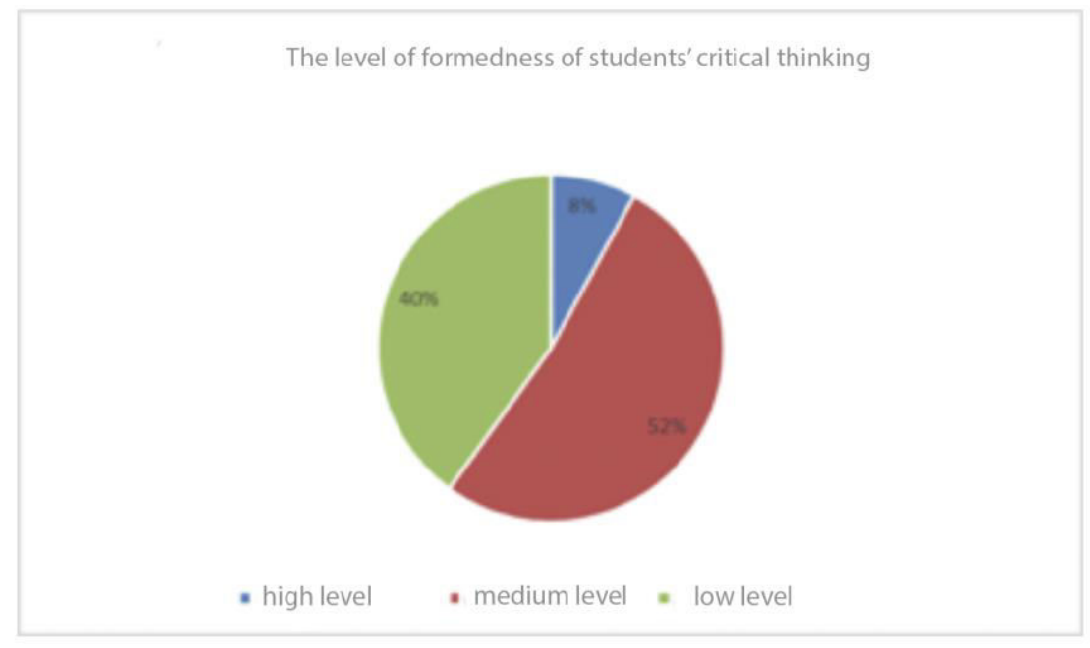

Figure 3: Results of the survey conducted among students.

Table 4: Levels of Indicators of Critical Thinking

\begin{tabular}{|c|c|c|c|}
\hline Levels & High level & Medium level & Low level \\
\hline \hline Results & 5 persons $(8 \%)$ & 34 persons $(52 \%)$ & 26 persons $(40 \%)$ \\
\hline Assessment & $90 \%$ and higher & $70 \%-89 \%$ & $69 \%$ and lower \\
\hline
\end{tabular}


of "system" reflects the real world being not as chaos, but in the form of discrete, ordered integrity, "quality nodes" [11]. In this regard, it is advisable to talk about the phenomenon of systematic-critical thinking.

A person is unlikely to be able to form critical thinking without considering the object of knowledge in a wider context. On the other hand, a systematic and versatile study of an object, taking into account its connections with a super-system, allows the student to develop skills and holistic knowledge of the surrounding reality. This is one of the important features of the implementation of the systems approach in the educational process. The systematic approach considers the object included in the system with other objects interconnected, and interacting with them, changing their properties under the influence of impacts in objects interconnected with it [11]. To form critical thinking of students with cerebral palsy, it is proposed to consider the following points:

1. The important prerequisite for the controlled formation of critical thinking is, first of all, the student's awareness of the concept and essence of critical thinking and a conscious movement towards this goal.

2. Integrity, depending on the individual properties of the parts, at the same time, determines what they should become for it, what function should fulfill, what properties should have. The "expedient" parts are the elements-result of the internal development of the whole, its product. Integrity is the unity of all elements-parts of the system; only in this way can the goals be achieved.

The ability to develop skills and holistic knowledge of the surrounding reality, carried out on the basis of a systematic approach, significantly increases the efficiency and quality of the formation of critical thinking. Holistic knowledge of the studied objects, as practice shows, is best done through systemic thinking, which also includes critical analysis. In addition, the same mental operations are at the core of systemic and critical thinking. Systemic thinking, which has wider functions in contrast to critical thinking, nevertheless, includes it in its orbit. The aforementioned, as well as the results of the study, allow us to talk about the possibility and expediency of the formation of systemic critical thinking in the subjects of training.
3. The goal allows us to design a system as an answer to the question of what needs to be done in order to achieve the goal. That is, in this case, the system is considered as a means to achieve the goals of training. In accordance with the goal, the structure of the system is formed, the components of which are most often used: subjects, content, methods, forms, and teaching aids. The teacher should formulate the goal, achieve recognition by all students, and show the ways and means by which critical thinking can be formed.

4. In the process of controlled formation of critical thinking, the self-government of students who actively use reflection in this process should dominate.

5. From the point of view of individualisation and differentiation of training, it is recommended to use "multilevel" training, which allows forming not only specific competencies for the application of knowledge, skills but also directly systematiccritical and critical thinking:

a) at the level of "standard" (answers to questions, problem-solving, tasks, exercises, independent work, etc., which meet the educational standard);

b) at the level of creativity - solving problems and task, completing tasks, exercises, independent work, etc., requiring creative skills;

c) at the research level (research solution of tasks and problems, implementation of scientific projects, tasks, independent work, preparation of essays, reports, articles, etc., requiring the skills of a system, research, creative, and other approaches).

At the same time, each of the above competencies involves the use of appropriate control and certification cards with three levels of complexity and difficulties of the theoretical questions, tasks, exercises, and tasks included in them [12].

6. Continuous monitoring of the process and the formation of students' systemic representations, skills, and abilities of critical and systematiccritical thinking should be combined with diagnostics of the state of personal characteristics of subjects of learning (cognitive activity, independence, abilities, and skills of self- 
management in cognitive and other activities, responsibility, self-discipline, creativity, etc.). Only in this case, it becomes possible to timely correct deviations arising in the process of training and education.

7. The periodic use of questionnaires, interviews, and other similar research methods allows expanding monitoring of the process and the results of the formation of critical and systematiccritical thinking of students with disorders of the musculoskeletal system.

8. The final interview with each student allows us to discuss his activities and the results obtained in the formation of critical and systematic-critical thinking and to give the necessary recommendations for this.

\section{DISCUSSION}

The concepts of the development of critical thinking are based on the ideas of the American researcher $E$. Glazer. He was the first to propose a set of certain skills that, in his opinion, relate specifically to critical thinking: the ability to recognise a problem and find solutions, to collect and organise the necessary information, to recognise unconfirmed assumptions and estimates; ability to show accuracy and selectivity in the use and perception of language means; the ability to interpret facts and information, evaluate evidence, detect the existence or absence of logical connections between judgments, draw legitimate conclusions and generalisations and cast doubt on them, rebuild their own belief systems and form correct judgments about everyday life phenomena [13].

The intellectual abilities described by E. Glazer were developed in the studies of R. Ennis, R. Paul, S. Norris, A. Fisher, and others [14]. The classification of critical thinking abilities of students with special needs based on a modified indicator of critical thinking is widespread (according to Facione-Angelo); it covers: interpretation of a problem (recognition of a problem and a description of it without bias, identification of the author's goal, topic or point of view), analysis of an alternative solution (identifying causation, analysis of the author's arguments), assessment (the ability to evaluate the plausibility of statements or other forms of statements (representations)), inference (the ability to learn and connect (connect) the elements necessary to draw valid conclusions), explanation (the ability to present convincingly and consistently the results of one's reasoning), self-regulation (introspection and self-correction) [15]. This approach allows us to measure the level of formation of critical thinking by defining criteria for the level of development of these skills [16].

Another classification of critical thinking skills includes the following: clarification of the problem - to formulate a problem accurately and clearly; assessment - to collect and evaluate relevant information, to identify evaluation criteria, evaluate arguments; inference - justification based on relevant criteria and standards, derives causation; problemsolving strategies - to suggest ways to solve the problem [4]. In accordance with the second approach, personality traits are identified that are indicators of the formation of critical thinking: tolerance; independence in judgments, assessments; reflexivity resistance to pressure from authorities; desire for truth; conviction; responsibility; fairness in assessments; empathy; readiness for dialogue [17]. In the authors' opinion, the main problem is the difficulty of reliable and valid measurement of these qualities of students with psychological disabilities [18].

This approach allows us to more accurately and fully identify the level of critical thinking based on a comprehensive assessment of intellectual skills and certain personal qualities. Critical thinking always involves searching for truth through dialogue, discussion, a tolerant attitude to the opposite point of view, the ability to listen and hear the interlocutor. Simultaneously, it is the analysis, synthesis, and evaluation of information, stated justifications, arguments, and evidence.

Thus, measuring the level of critical thinking is a rather laborious process. The complexity of this approach lies primarily in determining reliable and valid criteria in identifying the correlation between the level of development of intellectual skills and the formation of personality traits in the development of appropriate diagnostic tools. And although at present in pedagogical and psychological science the first approach to determining the level of critical thinking formedness through highlighting the corresponding intellectual skills and mental operations of critical thinking has become more widespread, it seems appropriate to further develop and disseminate in pedagogical theory and practice the third approach, such as more systemic in nature. 


\section{CONCLUSIONS}

The ability to develop skills and holistic knowledge of the surrounding reality, carried out on the basis of a systematic approach, significantly increases the efficiency and quality of the formation of critical thinking of students with disabilities. Holistic knowledge of the studied objects, as practice shows, is best done through systematic thinking, which also includes critical analysis. In addition, the same mental operations are at the core of systemic and critical thinking. Systemic thinking, which has wider functions in contrast to critical thinking, nevertheless includes it in its orbit.

For the first time, the phenomenon of systemic critical thinking has been studied. The possibility of its formation under the condition of active implementation of the systematic approach in the educational process is revealed. Those mentioned above, as well as the results of the study, make it possible to talk about the possibility and expediency of implementing a systematiccritical approach in the educational process and forming, on this basis, the appropriate system-critical thinking of "special" students in the subjects of training.

In this regard, the authors define systematic-critical thinking as a reflection of the surrounding reality, indirect and generalised on the basis of the principle of systemicity, associated with the implementation of the systemic-critical approach in cognitive and other human activities. Studies have also shown that fully the level of critical thinking formedness is characterised not only by intellectual skills or mental operations (analysis, synthesis, systematisation, generalisation, establishment of causation and reflection) but also by the formation of a certain student with disorders of the musculoskeletal system personal qualities such as selfdiscipline, responsibility, activity, creativity, selfregulation.

\section{REFERENCES}

[1] Duron R, Limbach B, Waugh W. Critical thinking framework for any discipline. International Journal of Teaching and Learning in Higher Education 2006; 17(2): 160-166.

[2] Levine SJ. The online discussion board. New Directions for Adult and Continuing Education 2007; 113: 67-74. https://doi.org/10.1002/ace.248
[3]

Barak M, Dori YJ. Enhancing higher order thinking skills among inservice science teachers via embedded assessment. Journal of Science Teacher Education 2009; 20(5): 459-474. https://doi.org/10.1007/s10972-009-9141-z

[4] Jacob SM, Sam HK. Perspectives on crtical thinking through online discussion forums in engineering mathematics. In: $K$. Elleithy, T. Sobh, M. Iskander, V. Kapila, M.A. Karim, A. Mahmood (Eds.), Technological developments in networking, education and automation. Netherlands: Springer, 2010; pp. 121126.

[5] Lunenburg FC. Critical Thinking and Constructivism Techniques for Improving Student Achievement. National Forum Teacher Education Journal 2011; 21(3): 1-9.

[6] Brookfield SD. Teaching for critical thinking, tools and techniques to help students question their questions. San Francisco: A Wiley Imprint, Jossey-Bass 2012.

[7] Choy SC, Pou SO. Reflective thinking and teaching practices: a precursor for incorporating critical thinking into the classroom? International Journal of Instruction 2012; 5(1): 167-182.

[8] Seibu MJ. Analyzing critical thinking skills using online discussion forums and CCTST. Procedia-Social and Behavioral Sciences 2012; 31: 805-809.

https://doi.org/10.1016/j.sbspro.2011.12.145

[9] Fedotovskaya El. The methodology for the development of critical thinking as an important factor in the formation of foreignlanguage communicative competence in specialized universities. Moscow: Russian Academy of Education, 2005.

[10] Denisinkova MV. The formation of intellectual skills of a future geography teacher based on the technology of critical thinking development. Bryansk: Bryansk State University named after academician I.G. Petrovsky 2010.

[11] Kuzmin VP. Epistemological problems of systemic knowledge. Moscow: Znaniye, 1983.

[12] Galiev TT, Abdyrov AM, Yesekeshova MD, Sagalieva JK. A systematic approach to advanced learning. Astana: Publishing house of KazATU named after Saken Seyfullin 2016.

[13] Bezanilla MJ, Fernández-Nogueira D, Poblete M, GalindoDomínguez $\mathrm{H}$. Methodologies for teaching-learning critical thinking in higher education: The teacher's view. Thinking Skills and Creativity 2019; 33: 244-254. https://doi.org/10.1016/..tsc.2019.100584

[14] Kulamikhina IV, Birova J, Alipichev AY, Vasbieva DG, Kalugina $\mathrm{OA}$. Developing communication and critical thinking through creative writing in English and French language: analysis of classroom management strategies. Komunikacie 2018; 20(1): 115-130.

[15] Seventika SY, Sukestiyarno YL, Scolastika M. Critical thinking analysis based on Facione (2015) - Angelo (1995) logical mathematics material of vocational high school (VHS). IOP Conference Series: Journal of Physics: Conference Series 2018 983: 46-52.

https://doi.org/10.1088/1742-6596/983/1/012067

[16] Facione PA. Critical thinking: What it is and why it counts 2013 Retrieved from: Insight Assessment https://www.nyack.edu/files/CT_What_Why_2013.pdf.

[17] Litvinova IS. The activities of the teacher of the humanities in the development of critical thinking of high school students. Tula: Tula State Pedagogical University named after L.N. Tolstoy, 2005.

[18] Eferova AR. Pedagogical conditions for the formation of critical thinking of students in the educational process of a technical university. Voronezh: Voronezh State University, 2010.

Received on 05-08-2020

Accepted on 26-08-2020

Published on 14-09-2020

DOI: https://doi.org/10.6000/2292-2598.2020.08.03.15

(C) 2020 Yessekeshova et al.; Licensee Lifescience Global.

This is an open access article licensed under the terms of the Creative Commons Attribution Non-Commercial License (http://creativecommons.org/licenses/by-nc/3.0/) which permits unrestricted, non-commercial use, distribution and reproduction in any medium, provided the work is properly cited. 